\title{
Resultaten van vijf jaar live chirurgie voor endo-urologische behandeling van urinewegstenen
}

\section{Zijn de uitkomsten in het gedrang?}

\author{
Jaap D. Legemate ${ }^{1} \cdot$ Richard C. Zieren $^{1} \cdot$ Joyce Baard ${ }^{1} \cdot$ Guido M. Kamphuis ${ }^{1}$ Jean J. M. C. H. de la Rosette
}

Published online: 15 February 2018

(c) The Author(s) 2018

\section{Samenvatting}

Deze retrospectieve studie vergelijkt de behandeluitkomsten voor urinewegstenen van live endo-urologische procedures (live EP) met die van routine endo-urologische procedures (routine EP). Over een periode van vijf jaar werden er 666 ureteroscopische (URS) en 182 percutane (PNL) niersteenbehandelingen verricht, waarvan 151 live EP's. Intraoperatieve complicaties tijdens URS traden op bij 3,2\% van de live EP's en 2,5\% van de routine EP's $(p=0,72)$ en postoperative complicaties bij 13,7\% van de live EP's en 8,8\% van de routine EP's $(p=0,13)$. Intraoperatieve complicaties tijdens PNL traden op bij 8,9\% van de live EP's en bij 5,6\% van de routine EP's $(p=0,52)$ en postoperatieve complicaties bij $28,6 \%$ van de live EP's en bij 34,9\% van de routine EP's $(p=0,40)$. Binnen de URS- en de PNL-groepen was er geen significant verschil in Clavien-Dindo-complicatiegraden. Multipele regressieanalyse toonde geen associatie tussen live EP en minder gunstige behandeluitkomsten. Live EP's, zoals uitgevoerd in deze setting, lijken behandeluitkomsten niet te benadelen wanneer deze worden vergeleken met routine EP's.

Trefwoorden stenen - urolithiasis $\cdot$ live chirurgie $\cdot$ ureterorenoscopie $\cdot$ percutane nefrolithotomie

\section{Outcome from five-year live endourological urinary stone treatment}

Are outcomes compromised?

\begin{abstract}
This retrospective study compares treatment outcomes for urinary stones of live surgical procedures (LSP) and routine surgical procedures (RSP). Over a five-year period, 666 ureteroscopic (URS) and 182 percutaneous (PNL) procedures were performed, of which 151 LSP's. Among the URS-groups, the intra- and postoperative complication rates were 3.2\% for LSP and $2.5 \%$ for RSP ( $p=0.72)$, respectively $13.7 \%$ for LSP and $8.8 \%$ for RSP $(p=0.13)$. Among the PNL-groups, the intra- and postoperative complication rate were $8.9 \%$ for LSP and 5.6\% for RSP ( $p=0.52$ ), respectively $28.6 \%$ for LSP and $34.9 \%$ for RSP $(p=0.40)$. There were no statistically significant differences in Clavien-Dindo complication grades within the URS- and PNL-groups. Multiple regression analyses revealed no association between LSP and less favorable outcomes as compared to RSP. Live surgical endourological demonstrations, as performed in this setting, do not seem to compromise outcomes.
\end{abstract}

Keywords stenen - urolithiasis - live chirurgie $\cdot$ ureterorenoscopie percutane nefrolithotomie

drs. Jaap D. Legemate

j.d.legemate@amc.uva.nl

1 afdeling Urologie, Academisch Medisch Centrum, Amsterdam, Nederland

\section{Introductie}

Live chirurgie is een populair educatiemiddel. Met het toenemen van de populariteit van live chirurgie worden de educatieve waarde, professionele en financiële belangen- 
verstrengeling, maar bovenal patiëntveiligheid, ter discussie gesteld $[1,2]$. Om de patiëntveiligheid te waarborgen, hebben meerdere chirurgische verenigingen richtlijnen opgesteld voor de uitvoering en organisatie van live chirurgie [3]. De European Association of Urology (EAU) introduceerde in 2014 een richtlijn met daarin ondersteunende informatie voor het organiseren en veilig uitvoeren van live chirurgie. Het belangrijkste principe van deze richtlijn is dat patiëntveiligheid te allen tijde de hoogste prioriteit heeft [1]. Buiten deze richtlijn is de literatuur met betrekking tot de veiligheid van live chirurgie binnen de urologie schaars. De meerderheid van de uitgevoerde studies zijn beleidspublicaties of enquêtes [1, 3-6]. De conclusies van deze studies zijn vaak gebaseerd op opinies en niet op empirisch onderzoek naar behandeluitkomsten. Inzicht in de behandeluitkomsten van live chirurgie zal een objectiever beeld geven over de veiligheid van dit educatiemiddel voor de patiënt.

In deze studie worden de uitkomsten van live endo-urologische procedures (live EP) voor de behandeling van urinewegstenen in het AMC vergeleken met die van routine endo-urologische procedures (routine EP).

\section{Materiaal}

\section{Uitkomsten}

De primaire uitkomst omvat het aantal intra- en postoperatieve complicaties met de Clavien-Dindogradering. Secundaire uitkomsten waren operatieduur, opnameduur, steenvrije status en het aantal heroperaties.

\section{Dataverzameling, definities en setting}

De data van elke opeenvolgende ureterorenoscopie (URS) en percutane nefrolithotomie (PNL) voor urinewegstenen in het Academisch Medisch Centrum (AMC) Amsterdam van januari 2011 tot en met juli 2015 werden retrospectief verzameld. Alle patiënten die een gecombineerde intrarenale chirurgische procedure (GIRC) ondergaan hadden, werden ingedeeld in de PNL-groep. De patiënten die een URS- of een PNL-procedure ondergaan hadden, werden onderverdeeld in twee groepen: live endo-urologische procedures en routine endo-urologische procedures. Een live EP werd gedefinieerd als een procedure die werd uitgevoerd omwille van educatieve doeleinden in het bijzijn van cursisten in de operatiekamer, of procedures die cursisten konden volgen via livestream [1]. Urologische live EP's worden in het AMC uitgevoerd sinds 2005, waarbij er op de eerste dag lezingen gegeven worden en op de tweede dag live EP's worden getoond. Binnen de studieperiode werden 45 cursussen gegeven. De cursus vond plaats in internationale setting, met cursisten en operateurs uit verschillende landen. De voertaal was Engels. Gastoperateurs en operateurs uit het AMC waren allen gespecialiseerde endo-urologen. De gastoperateurs waren vertrouwd met het instrumentarium en de setting op de operatiekamer. Een gastoperateur werd altijd vergezeld door een of meerdere endo-urologen uit het AMC.

\section{Studiepopulatie en dataverzameling}

Alle patiënten die tijdens de studieperiode endo-urologische steenverwijderingen ondergingen, werden geïncludeerd. Op cursusdagen werd er een combinatie van hoog- en laagcomplexe casus gemaakt, afhankelijk van beschikbare patiënten. De live geopereerde patiënten werden vooraf goed geïnformeerd over de operatiesetting en eventuele gastoperateurs. Alle patiënten gaven schriftelijk toestemming voor deelname. Demografische en klinische patiëntgegevens werden verzameld. De totale steenoppervlakte op beeldvorming werd berekend met de formule: lengte $\times$ breedte $\times 0,25 \times \pi[7,8]$.

De steenafmetingen werden bepaald op de coupe van de CT-scan waarop de steenoppervlakte het grootst was. In het geval van multipele stenen werd de som van de afzonderlijke steenoppervlaktes genomen.

\section{Uitkomsten en follow-up}

Intraoperatieve complicaties omvatten: bloedingen, ureterperforaties, ureterletsels, ureteravulsies en complicaties buiten de urinewegen. Postoperatieve complicaties waren: bloedingen, koorts $\left(>38,0^{\circ} \mathrm{C}\right)$, urineweginfecties, sepsis, interventiebehoevende pijn afwijkend van het verwachte beloop, percutane urinelekkage, complicaties buiten de urinewegen en overlijden. Deze complicaties werden gescoord volgens Clavien-Dindoclassificatie. Voor PNL-procedures werd de gevalideerde Clavien-Dindoscore voor PNL-procedures gebruikt [9, 10]. Het niet slagen van een procedure werd gedefinieerd door een mislukte toegang tot de ureter of het verzamelsysteem, waardoor de steen in situ bleef. Operatieduur werd voor URS gedefinieerd als het tijdsinterval tussen introductie van de scoop en het verwijderen van de scoop uit de urethra, en bij PNL tussen de punctie en het plaatsen van de nefrostomiekatheter. Wanneer er bij de PNL geen nefrostomiekatheter werd geplaatst, werd het verwijderen van de nefroscoop en de Amplatz-sheath als het einde van de procedure beschouwd. De totale followup duurde drie maanden. De steenvrije status werd zes tot acht weken na de ingreep vastgesteld middels echo of CTscan. Steenvrij werd gedefinieerd als de afwezigheid van fragmenten $>1 \mathrm{~mm}$ op CT of totale afwezigheid van fragmenten op echo. Indien postoperatieve beeldvorming ont- 
Tabel 1 Intra- en postoperatieve complicaties ureterorenoscopie urinewegstenen

\begin{tabular}{|c|c|c|c|c|}
\hline Uitkomst & $\begin{array}{l}\text { Live-URS } \\
n=95(14,3)\end{array}$ & $\begin{array}{l}\text { Routine-URS } \\
n=571(85,7)\end{array}$ & $p$-waarde & toets \\
\hline \multicolumn{5}{|l|}{ Intraoperatieve complicaties $n(\%)$} \\
\hline totaal & $3(3,2)$ & $14(2,5)$ & $p=0,72$ & $\mathrm{~B}$ \\
\hline bloeding & $1(1,1)$ & $3(0,5)$ & $p=0,46$ & B \\
\hline perforatie & $0(0)$ & $10(1,8)$ & $p=0,37$ & B \\
\hline avulsie & $0(0)$ & $0(0)$ & - & - \\
\hline overige & $2(2,1)$ & $1(0,2)$ & $p=0,055$ & $\mathrm{~B}$ \\
\hline totaal & 95 & 571 & & \\
\hline \multicolumn{5}{|l|}{ Postoperatieve complicaties n (\%) } \\
\hline totaal $^{\mathrm{a}}$ & $13(13,7)$ & $50(8,8)$ & $p=0,13$ & A \\
\hline bloeding & $0(0)$ & $3(0,5)$ & $p=1,00$ & $\mathrm{~B}$ \\
\hline koorts $(>38,0)$ & $7(7,4)$ & $19(3,3)$ & $p=0,080$ & $\mathrm{~B}$ \\
\hline urineweginfectie & $5(5,3)$ & $17(3,0)$ & $p=0,23$ & $\mathrm{~B}$ \\
\hline sepsis & $4(4,2)$ & $16(2,8)$ & $p=0,51$ & $\mathrm{~B}$ \\
\hline pijn & $0(0)$ & $13(2,3)$ & $p=0,23$ & B \\
\hline overlijden & $1(1,1)$ & $1(0,2)$ & $p=0,27$ & B \\
\hline overige & $2(2,1)$ & $1(0,2)$ & $p=0,21$ & B \\
\hline totaal & 95 & 571 & & \\
\hline Bloedtransfusies n (\%) & $0(0)$ & $6(1,1)$ & $p=1,00$ & B \\
\hline totaal & 94 & 571 & & \\
\hline \multicolumn{5}{|l|}{ Clavien-score $n(\%)$} \\
\hline geen & $82(86,3)$ & $521(91,2)$ & $p=0,12$ & A \\
\hline 1 & $0(0)$ & $6(1,1)$ & & \\
\hline 2 & $11(11,6)$ & $31(5,4)$ & & \\
\hline $3 \mathrm{a}$ & $0(0)$ & $6(1,1)$ & & \\
\hline $3 b$ & $0(0)$ & $3(0,5)$ & & \\
\hline $4 a$ & $1(1,1)$ & $3(0,5)$ & & \\
\hline $4 b$ & $0(0)$ & $0(0)$ & & \\
\hline 5 & $1(1,1)$ & $1(0,2)$ & & \\
\hline totaal & 95 & 571 & & \\
\hline Niet-geslaagde ingrepen $n(\%)$ & $8(8,4)$ & $30(5,3)$ & $p=0,23$ & B \\
\hline totaal & 95 & 571 & & \\
\hline Operatieduur in minuten, mediaan, (IKA) & $50,(40,5-68)$ & $41(25-63)$ & $p<0,001$ & $\mathrm{C}$ \\
\hline totaal $(n)$ & 95 & 570 & & \\
\hline Postoperatieve opnameduur in dagen, mediaan, (IKA) & $1,0,(1,0-1,0)$ & $1,0(1,0-1,0)$ & $p=0,83$ & $\mathrm{C}$ \\
\hline totaal $(n)$ & 94 & 571 & & \\
\hline Steenvrij $n(\%)$ & $58(63,0)$ & $366(67,7)$ & $p=0,39$ & A \\
\hline totaal & 92 & 541 & & \\
\hline \multicolumn{5}{|l|}{ Vastgesteld middels: $n(\%)$} \\
\hline computed tomography & $6(6,3)$ & $20(3,5)$ & 0,19 & A \\
\hline echo & $56(58,9)$ & $430(75,3)$ & $<0,001$ & A \\
\hline peroperatieve bevestiging & $26(27,4)$ & $106(18,6)$ & 0,046 & A \\
\hline overig & $7(7,4)$ & $15(2,6)$ & 0,017 & A \\
\hline totaal & 95 & 571 & & \\
\hline Heroperatie $n(\%)$ & $18(18,9)$ & $64(11,2)$ & $p=0,034$ & A \\
\hline totaal & 95 & 571 & & \\
\hline Heropname $<3$ maanden $n(\%)$ & $19(20,0)$ & $76(13,4)$ & $p=0,088$ & A \\
\hline totaal & 95 & 568 & & \\
\hline
\end{tabular}

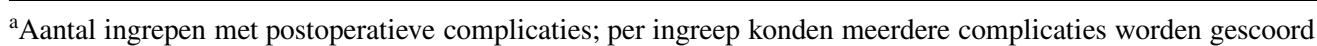
$I K A$ interkwartielafstand, $A$ Pearson chi-kwadraattoets, $B$ Fisher-exacttest, $C$ Mann-Whitney-U-toets 
Tabel 2 Intra- en postoperatieve complicaties percutane nefrolithotomie

\begin{tabular}{|c|c|c|c|c|}
\hline Uitkomst & $\begin{array}{l}\text { Live PNL } \\
n=56(30,8)\end{array}$ & $\begin{array}{l}\text { Routine PNL } \\
n=126(69,2)\end{array}$ & $p$-waarde & toets \\
\hline \multicolumn{5}{|c|}{ Intraoperatieve complicaties $n(\%)$} \\
\hline totaal & $5(8,9)$ & $7(5,6)$ & $p=0,52$ & $\mathrm{~B}$ \\
\hline bloeding $^{\mathrm{a}}$ & $3(5,4)$ & $4(3,2)$ & $p=0,68$ & $\mathrm{~B}$ \\
\hline perforatie & $0(0)$ & $2(1,6)$ & $p=1,0$ & $\mathrm{~B}$ \\
\hline mucosaal ureterletsel & $1(1,8)$ & $1(0,8)$ & $p=0,52$ & $\mathrm{~B}$ \\
\hline avulsie & $0(0)$ & $0(0)$ & - & - \\
\hline leverpunctie & $1(1,8)$ & $0(0)$ & $p=0,31$ & $\mathrm{~B}$ \\
\hline overige & $0(0)$ & $0(0)$ & - & - \\
\hline totaal & 56 & 126 & & \\
\hline \multicolumn{5}{|l|}{ Postoperatieve complicaties $n(\%)$} \\
\hline totaal & $16(28,6)$ & $44(34,9)$ & $p=0,40$ & A \\
\hline bloeding & $3(5,4)$ & $15(11,9)$ & $p=0,28$ & $\mathrm{~B}$ \\
\hline koorts $\left(>38,0^{\circ} \mathrm{C}\right)$ & $4(7,1)$ & $8(6,3)$ & $p=1,00$ & $\mathrm{~B}$ \\
\hline urineweginfectie & $6(10,7)$ & $7(5,6)$ & $p=0,22$ & $\mathrm{~B}$ \\
\hline sepsis & $1(1,8)$ & $8(6,3)$ & $p=0,29$ & $\mathrm{~B}$ \\
\hline urinelekkage & $3(5,4)$ & $2(1,6)$ & $p=0,17$ & $\mathrm{~B}$ \\
\hline overlijden & $0(0)$ & $1(0,8)$ & $p=1,00$ & $\mathrm{~B}$ \\
\hline overige & $2(3,6)$ & $10(7,9)$ & $p=0,35$ & $\mathrm{~B}$ \\
\hline totaal & 56 & 126 & & \\
\hline Aantal bloedtransfusies $n(\%)$ & $3(5,4)$ & $9(7,1)$ & $p=0,76$ & B \\
\hline totaal & 56 & 126 & & \\
\hline
\end{tabular}

brak, werd het intraoperatief ontbreken van restfragmenten $>1 \mathrm{~mm}$ aangehouden om een steenvrije status af te geven.

\section{Statistische analyse}

Voor vergelijkende analyse werd gebruikgemaakt van Pearson chi-kwadraat- of de Fisher-exacttest voor categorische variabelen, en de Mann-Whitney-U-toets voor niet normaal verdeelde, continue variabelen. Om de associatie tussen live EP en uitkomsten te analyseren en te vergelijken met routine-EP werden lineaire en logistische regressieanalyses verricht. Uitkomsten werden gecorrigeerd voor confounders. Voor URS waren de confounding variabelen: steengrootte, renale anomalieën en steenlokalisatie. Een confounder voor PNL was de steengrootte. Voor alle analyses werd het niveau van statistische significantie gezet op $p<0,05$. De analyses werden uitgevoerd met IBM SPSS 23.0.

\section{Resultaten}

\section{Patiënt- en procedurele kenmerken}

Er werden 666 URS en 182 percutane ingrepen geïncludeerd. In de URS-groep waren 95 (14,3\%) ingrepen live EP. In de percutane groep waren $56(30,8 \%)$ ingrepen live
EP. De patiëntkarakteristieken van de live- en routine-EPgroepen kwamen goed overeen. Een uitzondering hierop was het percentage renale anomalieën (hoefijzernier, ectopische nier en gemalroteerde nier), dat significant hoger was in de live-URS-groep dan in de routine-URS-groep.

In de live-URS-groep had een steen een gemiddelde oppervlakte van $91 \mathrm{~mm}^{2}$ en in de routine-URS-groep was dat $48 \mathrm{~mm}^{2}(p<0,001)$. In de live-URS-groep waren de stenen vaker in de nier gelokaliseerd dan in de routine-URSgroep $(84,2 \%$ vs. $49,7 \% ; p<0,001)$. Er was geen significant verschil in het aantal pre- en postoperatief geplaatste ureterstents.

Voor percutane ingrepen had een steen een gemiddelde oppervlakte van $389 \mathrm{~mm}^{2}$ in live-EP-groep en $280 \mathrm{~mm}^{2}$ in de routine-EP-groep $(p=0,039)$. Bij 51,8\% van de live EP's en $42,9 \%$ van de routine EP's had de patiënt stenen in multipele anatomische locaties in de nier of ureter. Bij $83,9 \%$ van de live EP's en 34,9\% van de routine EP's werd een GIRC verricht $(p<0,001)$.

\section{Ureteroscopische ingrepen}

Descriptieve data omtrent complicaties en secundaire uitkomsten voor URS worden weergegeven in tab. 1. $\mathrm{Er}$ was geen significant verschil in intraoperatieve complicaties $(3,2 \%$ bij live EP versus $2,5 \%$ bij routine EP; $p=0,72)$, noch in postoperatieve complicaties $(13,7 \%$ na live EP ver- 
Tabel 2 (Vervolg)

\begin{tabular}{|c|c|c|c|c|}
\hline Uitkomst & $\begin{array}{l}\text { Live PNL } \\
n=56(30,8)\end{array}$ & $\begin{array}{l}\text { Routine PNL } \\
n=126(69,2)\end{array}$ & $p$-waarde & toets \\
\hline \multicolumn{5}{|l|}{ Clavien-score $n(\%)$} \\
\hline geen & $40(71,4)$ & $82(65,1)$ & $p=0,51$ & A \\
\hline 1 & $1(1,8)$ & $3(2,4)$ & & \\
\hline 2 & $11(19,6)$ & $18(14,3)$ & & \\
\hline $3 \mathrm{a}$ & $2(3,6)$ & $14(11,0)$ & & \\
\hline $3 b$ & $2(3,6)$ & $5(4,0)$ & & \\
\hline $4 a$ & $0(0)$ & $3(2,4)$ & & \\
\hline $4 b$ & $0(0)$ & $0(0)$ & & \\
\hline 5 & $0(0)$ & $1(0,8)$ & & \\
\hline totaal & 56 & 126 & & \\
\hline Niet geslaagde ingrepen $n(\%)$ & $1(1,8)$ & $8(6,4)$ & $p=0,28$ & $\mathrm{~B}$ \\
\hline totaal & 56 & 125 & & \\
\hline Operatieduur in minuten, mediaan (IKA) & $80(62-101,5)$ & $75(57-94)$ & $p=0,21$ & $\mathrm{C}$ \\
\hline totaal $(n)$ & 56 & 125 & & \\
\hline Postoperatieve opnameduur in dagen, mediaan, (IKA) & $4(3-5)$ & $3(2-4)$ & $p=0,086$ & $\mathrm{C}$ \\
\hline totaal $(n)$ & 56 & 119 & & \\
\hline $\begin{array}{l}\text { Steenvrij } n(\%) \\
\text { totaal }\end{array}$ & $\begin{array}{l}26(50,0) \\
52\end{array}$ & $\begin{array}{l}45(38,5) \\
117\end{array}$ & $p=0,16$ & A \\
\hline \multicolumn{5}{|l|}{ Vastgesteld middels: $n(\%)$} \\
\hline computed tomography & $11(21,6)$ & $20(17,5)$ & $p=0,33$ & A \\
\hline echo & $35(68,6)$ & $70(61,4)$ & & \\
\hline retrograde pyelogram & $0(0)$ & $2(1,8)$ & & \\
\hline peroperatieve bevestiging & $5(9,8)$ & $22(19,3)$ & & \\
\hline totaal & 51 & 114 & & \\
\hline Tijd tot follow-up in weken, mediaan (IKA) & $8(12)$ & $6(4)$ & $p=0,008$ & $\mathrm{C}$ \\
\hline totaal $(n)$ & 46 & 91 & & \\
\hline Heroperatie $n(\%)$ & $14(25,5)$ & $45(36,0)$ & $p=0,16$ & A \\
\hline totaal & 55 & 124 & & \\
\hline Heropname $<3$ maanden $n(\%)$ & $18(32,1)$ & $47(37,6)$ & $p=0,48$ & A \\
\hline totaal & 56 & 125 & & \\
\hline
\end{tabular}

${ }^{\mathrm{a}}$ Er waren geen intraoperatieve bloedtransfusies nodig

IKA interkwartielafstand, $A$ Pearson chi-kwadraattoets, $B$ Fisher-exacttest, $C$ Mann-Whitney-U-toets

sus $8,8 \%$ na routine $\mathrm{EP} ; p=0,13$ ). In beide groepen werd de meerderheid van de complicaties als Clavien 2 geclassificeerd. In zowel de live- als de routine-EP-groep trad één Clavien-5-complicatie op.

De mediane operatieduur was 50 minuten in de live-EPgroep en 41 minuten in de routine-EP-groep $(p<0,001)$. De mediane opnameduur was in beide groepen één dag. In de live-URS-groep was $63,0 \%$ steenvrij, ten opzichte van $67,7 \%$ in de routine-URS-groep $(p=0,39)$. Een heroperatie werd verricht bij $18,9 \%$ van de patiënten na live EP en bij $11,2 \%$ van de patiënten na routine $\mathrm{EP}(p=0,034)$.

\section{Percutane ingrepen}

Descriptieve data omtrent complicaties en secundaire uitkomsten voor percutane ingrepen worden weergegeven in tab. 2. Er werden geen significante verschillen gevonden in percentage intraoperatieve complicaties $(8,9 \%$ tijdens live EP versus 5,6\% tijdens routine EP; $p=0,052$ ), noch in postoperatieve complicaties $(28,6 \%$ in live EP versus $34,9 \%$ in routine $\mathrm{EP} ; p=0,40$ ). Daarnaast was er geen verschil in Clavien-Dindocomplicatiegradaties. In de routine-EPgroep trad één Clavien-5-complicatie op. De mediane operatieduur was 80 minuten voor live $\mathrm{EP}$ en 75 minuten voor routine $\mathrm{EP}(p=0,21)$. De mediane opnameduur was vier dagen na live EP en drie dagen na routine $\mathrm{EP}(p=0,086)$. $\mathrm{Na}$ live EP was $50,0 \%$ van de patiënten steenvrij ten opzichte van $38,5 \%$ van de patiënten na routine $\operatorname{EP}(p=0,16)$. Een heroperatie werd verricht bij $25,5 \%$ van de patiënten na een live EP en bij 36,0\% van de patiënten na routine EP $(p=0,16 \%)$. 
Hier staat een advertentie.

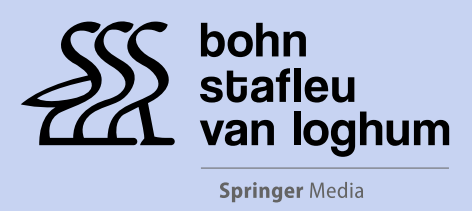

Houten 2018 
Hier staat een advertentie.

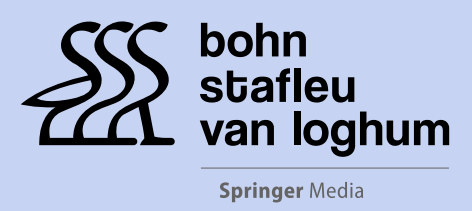

Houten 2018 


\section{Regressiemodellen}

Multiple regressieanalyses voor zowel URS als PNL lieten geen associatie zien tussen het optreden van meer of minder gunstige uitkomsten voor live EP bij vergelijking van deze uitkomsten met routine EP.

\section{Discussie}

De belangrijkste bevinding van deze studie is dat er geen statistisch significante verschillen zijn in de aantallen en ernst van zowel intra- als postoperatieve complicaties tussen live EP en routine EP voor urinewegstenen. In de liveURS-groep doen zich relatief meer complicaties voor dan in de routine-URS-groep. Het verschil is echter niet statistisch significant en kan mogelijk worden verklaard door externe factoren. Allereerst zijn de stenen in de live-URSgroep bijna twee keer zo groot als in de routine-URS-groep. Het regressiemodel heeft bevestigd dat dit mede heeft bijgedragen aan de langere operatieduur van de live-URS-groep. Bij de behandeling van grote stenen of van stenen op multiple locaties, met daarbij een langere operatieduur, kan het risico op complicaties toenemen. Daarnaast zijn in de liveURS-groep relatief gezien meer nierstenen verwijderd dan in de routine-URS-groep. Literatuur laat zien dat het aantal complicaties over het algemeen hoger is bij URS voor nierstenen dan bij URS voor ureterstenen [11, 12]. In de live-URS-groep waren bovendien meer patiënten met renale anomalieën ingedeeld dan in de routine-URS-groep. Uit de literatuur is bekend de aanwezigheid van een renale anomalie kan bijdragen aan een hoger complicatierisico [13].

In deze studie valt het aantal complicaties na URS binnen de in de literatuur beschreven waarde van $5-15 \%$. Bij PNL ligt het percentage complicaties hoger dan de uit de literatuur bekende $15-21 \%$ [14, 15]. De meeste postoperatieve complicaties zijn als Clavien 1 of 2 geclassificeerd en vereisen geen invasieve interventies. Wel doen zich drie Clavien-5-complicatie voor, één in de live-URS-groep, één in de routine-URS-groep en één in de routine-PNL-groep, in alle gevallen bij patiënten met uitgebreide multimorbiditeit.

De karakteristieken van geopereerde patiënten in de liveEP-groepen zijn vergelijkbaar met die van de patiënten in routine-EP-groepen. Daarom zijn de voor live EP geselecteerde patiënten een goede representatie van gebruikelijke gevallen in een steenexpertisecentrum. We denken niet dat de Clavien-5-complicatie (gevolg van een aspiratiepneumonie 26 dagen postoperatief) die optrad na een live URS te voorkomen was geweest wanneer de patient zou zijn geopereerd volgens de routineprocedure.

De beschreven mortaliteit na steenbehandeling middels URS is eerder in een eerdere grote multicenter studie vast- gesteld op 0,02\% en voor PNL op 0,05\% [15, 16]. De mortaliteit van 2 op $666(0,3 \%)$ voor URS en 1 op $182(0,5 \%)$ voor PNL in dit cohort is hoog. In de betreffende casus zijn de pro's en contra's van alternatieven voor endoscopische behandeling nauwkeurig afgewogen in een urologisch team en met de patiënt en familie. Deze casus reflecteren de hoogcomplexe situaties waarmee we steeds vaker te maken krijgen en waarin soms, helaas, ernstige complicaties optreden.

Ook voor secundaire uitkomstmaten van URS zijn er verschillen gevonden tussen de live- en routine-EP-groepen. De langere operatieduur en het hogere percentage heroperaties bij live URS kan mogelijk worden verklaard door een grotere mediane steengrootte vergeleken met routine EP. Daarnaast kunnen educatieve momenten gedurende live chirurgie de operatieduur verlengen. Van de operateur wordt uitleg verwacht en cursisten mogen vragen stellen. Tijdens live EP is het vermogen om te multitasken van essentieel belang, waarbij de uitdaging is om een educatieve maar veilige en effectieve ingreep uit te voeren, zonder de operatietijd onnodig te verlengen.

Het hogere percentage steenvrije patiënten in de livePNL-groep kan mogelijk worden verklaard door het relatief hogere antal GIRC in vergelijking met de routinePNL-groep. Tijdens live percutane ingrepen was er vaker een tweede operateur beschikbaar, zodat de steen tegelijkertijd antegraad en retrograad kon worden benaderd [17]. Een verklaring voor het frequenter uitvoeren van GIRC tijdens live EP is dat de betreffende patiënten vaker stenen op meerdere locaties hadden en het vaker grotere stenen betrof.

Het percentage patiënten dat steenvrij is in deze studie is in de totale URS-groep 67 en in de PNL-groep 42. Het percentage patiënten dat steenvrij is varieert in de literatuur van 50-100 na URS en van 55-85 na PNL [14, 18, 19]. Er zijn verschillende verklaringen mogelijk voor deze toch tegenvallende resultaten. Een eerste mogelijke verklaring is de afkapwaarde om steenvrije status af te geven. Deze is, met een afkapwaarde van restfragmenten van $>1 \mathrm{~mm}$ in vergelijking met de literatuur vrij streng. Ten tweede is het aantal procedures waarbij het niet mogelijk was om de steen in de primaire operatie te bereiken in de berekening meegenomen (5,7\% de URS-groep). Ten derde zijn er veel patiënten met grote stenen behandeld. Deze grote stenen zijn waar nodig in meerdere tempi behandeld. Ten slotte kunnen trainings- en onderwijsomstandigheden invloed hebben op de uitkomsten van zowel live als routine EP.

De verschillen in uitkomsten tussen live EP en routine EP lijken goed te verklaren. Na correctie voor verschillen tussen de groepen middels multiple regressieanalyse, wordt live chirurgie niet duidelijk geassocieerd met betere of minder gunstige uitkomsten vergeleken met routine-ingrepen. 
Hoewel de waargenomen verschillen niet statistisch significant zijn, zijn er wel trends waarneembaar. Er is op het gebied van intra- en postoperatieve complicaties, steenvrije status, operatieduur en het aantal heroperaties sprake van een trend richting minder gunstige uitkomsten in de liveURS-groep. Na correctie voor confouders is deze trend bevestigd ten aanzien van postoperatieve complicaties. Voor de live-PNL-groep is er een trend richting minder gunstige uitkomsten wat betreft intraoperatieve complicaties en operatieduur. Voor intraoperatieve complicaties is de trend bevestigd na correctie. Afgezien van de mogelijk ongunstige effecten van live chirurgie zijn er ook trends waarneembaar ten gunste van live chirurgie, zoals minder postoperatieve complicaties, meer steenvrije patiënten en minder herbehandeling na live PNL.

We kunnen deze trends niet ontkennen en het is uiterst belangrijk toekomstige resultaten zorgvuldig te monitoren en met een kritische blik naar de veiligheid van live chirurgie te blijven kijken.

Voor zover wij weten zijn er geen studies die de uitkomsten van live EP vergelijken met die van routine EP. Binnen de urologie vergeleken Mullins et al. 39 robotgeassisteerde partiële nefrectomieën die werden uitgevoerd als live procedure met 847 routine-ingrepen, en vonden geen statistisch significante verschillen in operatieduur, warme ischemietijd, positieve resectievlakken en complicaties [20]. De auteurs concludeerden dat live robotchirurgie veilig kan worden uitgevoerd [20]. Binnen de gastro-enterologie zijn de uitkomsten van endoscopische retrograde chalangiopancreaticografiën (ERCP) die werden uitgevoerd als live demonstratie vergeleken met standaardprocedures [21]. Dit werd gedaan door Liao et al., die hiertoe een grote multicenterstudie verrichtte, waarin 406 live procedures werden gematcht met controlecasus. Het totaal antal complicaties na live ERCP was niet significant verschillend van routine ERCP. Er was een klein maar significant verschil in geslaagde behandelingen ten nadele van live ERCP $(94,1 \%$ vs. 97,5\%; $p=0,021)$. Behandelsucces en complicaties waren vergelijkbaar wanneer de procedure werd uitgevoerd door een lokale, binnenlandse of buitenlandse gastbehandelaar [21]. Wat betreft het aantal complicaties komen de bevindingen van de bovengenoemde studie overeen met die van ons.

Bij de organisatie van live chirurgie dienen organisatoren en deelnemers zich te houden aan de gestelde regels. De EAU gedragscode voor live operaties kan bijdragen aan het veilig organiseren van een live chirurgisch evenement [1]. Het belangrijkste aspect tijdens live chirurgie blijft het bewaken van de patiëntveiligheid. Dit omvat niet alleen fysieke veiligheid tijdens en na de ingreep, maar ook het respecteren van de privacy en autonomie. Sociale media is een groeiend medium om kennis te delen. Tijdens bijeenkomsten wordt met regelmaat beeldmateriaal van patiënten gedeeld via sociale media. Ook wanneer het materiaal niet tot de patiënt te herleiden valt, heeft de patiënt vaak geen toestemming gegeven om de informatie via internet te delen. Een ieder die deelneemt aan live chirurgie dient zich hiervan bewust te zijn en de privacy van patiënten te allen tijde te respecteren.

Deze studie ondersteunt de aanname dat endo-urologische steenverwijdering tijdens live EP de patiëntveiligheid niet in gevaar brengt. Toch is terughoudendheid geboden bij het trekken van een ferme conclusie.

Een beperking van deze studie is de retrospectieve opzet. Dit retrospectieve studiedesign kan een mogelijke onderschatting geven van het aantal complicaties dat optreedt. Verder is de studie uitgevoerd in slechts één ziekenhuis met een beperkte groep endo-urologen voor wie live chirurgie gedurende de jaren mogelijk meer routine is geworden. Het merendeel van de geïncludeerde operaties is uitgevoerd door twee ervaren endo-urologen: een lokale operateur en een gastoperateur. Gastoperateurs waren in overgrote meerderheid van de gevallen vertrouwd met de omstandigheden, het instrumentarium en de omgeving. Met inachtneming van de bovenstaande studiesetting moeten we concluderen dat de bevindingen van deze studie niet direct te extrapoleren zijn naar uitkomsten van live chirurgie tijdens grote conferenties met een groot aantal toeschouwers.

Het evalueren van een mogelijk verschil in uitkomsten van live EP die is uitgevoerd door lokale en gastoperateurs was geen studiedoel binnen het huidige project. De evaluatie van het verschil in uitkomsten tussen gastoperateurs en lokale operateurs is samen met het analyseren van de uitkomsten van live chirurgie op grote conferenties een interessant gebied voor toekomstig onderzoek.

\section{Conclusie}

In deze studie zijn geen statistisch significante verschillen gevonden tussen de uitkomsten van endoscopische urinewegsteenbehandelingen tijdens live operaties vergeleken met operaties in routinesetting. Desalniettemin zijn er wel trends waarneembaar, waarbij de uitkomsten van live chirurgie minder gunstig lijken dan die van routine chirurgie. Dit betreft met name de uitkomsten van ureterorenoscopie. Bij het live uitvoeren van chirurgische procedures is een zeer zorgvuldige werkwijze en het scherp monitoren van uitkomsten van essentieel belang.

Open Access This article is distributed under the terms of the Creative Commons Attribution 4.0 International License (http:// creativecommons.org/licenses/by/4.0/), which permits unrestricted use, distribution, and reproduction in any medium, provided you give appropriate credit to the original author(s) and the source, provide a link to the Creative Commons license, and indicate if changes were made. 


\section{Literatuur}

1. Artibani W, Ficarra V, Challacombe BJ, et al. EAU policy on live surgery events. Eur Urol. 2014;66(1):87-97.

2. Kallmes DF, Cloft HJ, Molyneux A, et al. Live case demonstrations: Patient safety, ethics, consent, and conflicts. Lancet. 2011;377(9776):1539-41.

3. Duty B, Okhunov Z, Friedlander J, et al. Live surgical demonstrations: an old, but increasingly controversial practice. Urology. 2012;79(5):1185.e7-11.

4. Khan SAA, Chang RTM, Ahmed K, et al. Live surgical education: a perspective from the surgeons who perform it. BJU Int. 2014;114(1):151-8.

5. Finch W, Masood J, Buchholz N, et al. Would you want to be the patient? "Live surgical broadcast" or "as-live unedited surgical broadcast”. J Endourol. 2015;29(7):821-9.

6. Phan YC, Segaran S, Wiseman O, et al. Which is better? "Live" surgical broadcasts vs "as-live" surgical broadcasts. J Endourol. 2016;30(9):1022-8.

7. Ito $\mathrm{H}$, Kawahara $\mathrm{T}$, Terao $\mathrm{H}$, et al. Evaluation of preoperative measurement of stone surface area as a predictor of stone-free status after combined ureteroscopy with holmium laser lithotripsy: a single-center experience. J Endourol. 2013;27(6):715-21.

8. Tiselius H-G. How efficient is extracorporeal shockwave lithotripsy with modern lithotripters for removal of ureteral stones? J Endourol. 2008;22(2):249-55.

9. Dindo D, Demartines N, Clavien P-A. Classification of surgical complications. Ann Surg. 2004;240(2):205-13.

10. De La Rosette J, Opondo D, Daels FPJ, et al. Categorisation of complications and validation of the Clavien score for percutaneous nephrolithotomy. Eur Urol. 2012;62(2):246-55.

11. Castro PE, Osther PJS, Jinga V, et al. Differences in ureteroscopic stone treatment and outcomes for distal, mid-, proximal, or multiple ureteral locations: The clinical research office of the endourological society ureteroscopy global study. Eur Urol. 2014;66(1):102-9.

12. Skolarikos A, Gross AJ, Krebs A, et al. Outcomes of flexible ureterorenoscopy for solitary renal stones in the CROES URS global study. J Urol. 2015;194(1):137-43.

13. Baş O, Tuygun C, Dede O, et al. Factors affecting complication rates of retrograde flexible ureterorenoscopy: analysis of
1571 procedures - a single-center experience. World J Urol. 2016;35(5):819-26.

14. Lopes T, Sangam K, Alken P, et al. The clinical research office of the Endourological Society Percutaneous Nephrolithotomy Global Study: tract dilation comparisons in 5537 patients. J Endourol. 2011;25(5):755-62.

15. Türk C, Petř́k A, Sarica K, et al. EAU Guidelines on interventional treatment for urolithiasis. Eur Urol. 2016;69(3):475-82.

16. Rosette J de la, Denstedt J, Geavlete P, et al. The clinical research office of the endourological society ureteroscopy global study: indications, complications, and outcomes in 11,885 patients. J Endourol. 2014;28(2):131-9.

17. Hamamoto S, Yasui T, Okada A, et al. Endoscopic combined intrarenal surgery for large calculi: simultaneous use of flexible ureteroscopy and mini-percutaneous nephrolithotomy overcomes the disadvantageous of percutaneous nephrolithotomy monotherapy. J Endourol. 2014;28(1):28-33.

18. Cloutier J, Anson K, Giusti G, et al. Update of the ICUD-SIU consultation on stone technology behind ureteroscopy. World J Urol. 2017;35(9):1353-9.

19. Emmott AS, Brotherhood HL, Paterson RF, Lange D, Chew BH. Complications, re-intervention rates, and natural history of residual stone fragments after percutaneous nephrolithotomy. J Endourol. 2018;32:28.

20. Mullins JK, Borofsky MS, Allaf ME, et al. Live robotic surgery: are outcomes compromised? Urology. 2012;80(3):602-6.

21. Liao Z, Li Z-S, Leung JW, et al. How safe and successful are live demonstrations of therapeutic ERCP? A large multicenter study. Am J Gastroenterol. 2009;104(1):47-52.

drs. Jaap D. Legemate arts-onderzoeker urologie

drs. Richard C. Zieren arts-assistent urologie

drs. Joyce Baard uroloog

drs. Guido M. Kamphuis uroloog

prof. dr. Jean J.M.C.H. de la Rosette uroloog 